\title{
Participación y Comunicación. Hacia la legitimidad de las políticas públicas de reputación de los territorios
}

\author{
Dra. María José Cerdá Bertomeu | mjcerda@protocoloimep.com \\ Instituto Mediterráneo de Estudios de Protocolo
}

Palabras clave

Marca territorio, diplomacia pública, legitimidad, gobernanza, comunicación interna

\section{Sumario}

1. Introducción. Hacia la legitimidad de las políticas públicas de reputación de los territorios. 2. La participación de los públicos internos en las políticas reputacionales. 3. Las redes de marcas públicas y privadas. Cobranding y arquitectura de marcas en las políticas reputacionales. 4. La comunicación para la legitimidad en las políticas reputacionales. 5. Consideraciones Finales 6. Bibliografía. 7. Notas 8. Agradecimientos

\section{Resumen}

En la praxis, los territorios, por creencia o por necesidad práctica, impulsan activament políticas públicas destinadas a mejorar su imagen externa y su reputación. Para este fin, desarrollan proyectos de marcas territorio (place branding) y políticas de diplomacia pública (public diplomacy). En este artículo se plantean los aspectos cruciales que, desde el sector público se han de tener en cuenta, en los procesos de creación y de gestión de una marca territorio y en la puesta en marcha de políticas de diplomacia pública, para que se consideren legítimas y obtengan el apoyo interno de la sociedad del territorio.

\section{Cómo citar este texto:}

María José Cerdá Bertomeu (2017): "Participación y Comunicación. Hacia la legitimidad de las políticas públicas de reputación de los territorios", en Miguel Hernández Communication Journal, nº, pp. 643 a 669. Universidad Miguel Hernández, UMH (ElcheAlicante). Recuperado el $\_$de de 20 de: link del artículo en mhjournal.org] 


\section{Participation and Communication. Towards the legitimacy of the public policies of reputation of the territories}

Dra. María José Cerdá Bertomeu | mjcerda@protocoloimep.com

Instituto Mediterráneo de Estudios de Protocolo

\section{Keywords}

Place branding, public diplomacy, legitimacy, governance, internal communication

\section{Summary}

1. Introduction. Towards the legitimacy of the public policies of reputation of the territories. 2 . The participation of internal audiences in reputational policies. 3. Public and private brand networks. Cobranding and brand architecture in reputational policies. 4 . Communication for legitimacy in reputational policies. 5. Final Considerations 6. Bibliography. 7. Notes 8. Acknowledgment

\begin{abstract}
Places encourage active public policies to improve its image and its reputation outside. To this end, develops place branding and public diplomacy policies. This article outlines the crucial areas that, from the public sector need to taken into consideration in the process of creating and managing place brands and public diplomacy policies, in order to be legitimated and to obtain internal support.
\end{abstract}

How to cite this text:

María José Cerdá Bertomeu (2017): "Participation and Communication. Towards the legitimacy of the public policies of reputation of the territories", en Miguel Hernández Communication Journal, no8, pp. 643 to 669, Universidad Miguel Hernández, UMH (Elche-Alicante). Accessed 20 _ in: [paper link in mhjournal.org] 


\section{Introducción. Hacia la legitimidad de las políticas públicas de reputación de los territorios}

\subsection{Las políticas públicas de reputación de los territorios: las marcas territorio y la diplomacia pública.}

En la praxis, los territorios, por creencia o por necesidad práctica, impulsan activamente políticas públicas destinadas a mejorar su imagen externa y su reputación (Merkelsen y Rasmusen, 2016). Para este fin, desarrollan proyectos de marcas territorio (place branding) y políticas de diplomacia pública (public diplomacy).

Las marcas territorio son una respuesta a la competencia globalizada con el fin de beneficiar socioeconómicamente a los territorios donde se crean (Lucarelli, 2015). Son marcas públicas impulsadas por actores públicos y privados pertenecientes a las Administraciones Públicas, a las empresas privadas y a la sociedad civil de un territorio. Dada la naturaleza pública de este tipo de marcas, el sector público juega un papel especialmente relevante en el diseño y la gestión de estas políticas reputacionales, porque define y gestiona el interés general de la sociedad, establece normativas y desarrolla acciones para mejorar la competitividad de los territorios y la calidad de vida de sus ciudadanos (Ooi, 2011).

Para Zenker y Petersen (2014), la marca territorio (ciudad, región, país, destino, entre otras) es una red de asociaciones basada en las expresiones de las dimensiones de un territorio (físicas, políticas, económicas, socioculturales) dirigida a todos sus stakeholders internos y externos. Klijn, Eshuis y Braun (2012) señalan que es una potente herramienta de gestión pública destinada a dar soluciones a las problemáticas del territorio y a proyectar una imagen deseada para éste. Como herramienta de gestión pública, requiere de la puesta en marcha de políticas públicas transversales y congruentes que refuercen el posicionamiento estratégico deseado. Desde esta visión, una marca territorio sirve para gestionar y comunicar los activos territoriales y canalizar una 'narrativa colectiva de marca' (Kavaratzis, 2012), orientada al desarrollo territorial (De San Eugenio, 2012).

Destaca De San Eugenio-Vela (2013), que la diplomacia pública, a diferencia de la diplomacia tradicional ejercida por los Estados, puede ser entendida como la 'diplomacia de la opinión pública'. En la diplomacia pública las acciones están dirigidas al conjunto de las opiniones públicas existentes en los territorios (relaciones government-to-people y people-to-people) (Noya, 2005). 
Para Anholt (2007), es una herramienta para las relacionales internacionales y de comunicación externa, que sirve para mejorar la imagen de un territorio en la opinión pública internacional, su reputación y por ende, las actitudes y el comportamiento de los públicos externos hacia ésta. En la consecución de ciertos objetivos estratégicos, la diplomacia pública puede utilizar acciones de carácter informativo, cultural, o de entretenimiento, entre otras. Las acciones destinadas a mejorar la percepción del territorio, prevenir potenciales conflictos o internacionalizar empresas locales son habituales en las políticas de diplomacia pública (Manfredi, 2011). Los objetivos últimos a conseguir pueden ser diversos (de naturaleza cultural, política o económica) pero en todo caso, se persigue generar una influencia positiva y un mayor compromiso de la contraparte que permita el establecimiento relaciones ganar-ganar entre los territorios.

A pesar de estas aportaciones, no existe una conceptuación única y compartida de lo que son ni las marcas territorio ni la diplomacia pública (Skinner, 2008). De hecho, la relación entre estos dos conceptos ha sido tan controvertida como recurrente (De San Eugenio-Vela, 2013). De entre las múltiples conceptuaciones se puede señalar que, básicamente, se encuentran tres visiones distintas en la literatura.

En la primera de ellas, la diplomacia pública es una parte de la marca territorio, una herramienta al servicio del proyecto de marca territorio que forma parte de la dimensión relacional y comunicacional de la marca. Desde esta visión, una marca territorio es más que una herramienta relacional y comunicacional pues tiene implicaciones en la gobernanza y el desarrollo de un territorio. Los partidarios de esta perspectiva defienden que la comunicación por si misma no influye en las percepciones de las opiniones públicas sobre un territorio (Anholt, 2007). En palabras de Anholt (2008) "las comunicaciones no son un sustituto de las políticas públicas (...) alterar la imagen de un país o una ciudad puede requerir algo un poco más sustancial que el diseño gráfico, la publicidad o las campañas de relaciones públicas” (p.1).

Una segunda visión, señala que la marca territorio es un instrumento al servicio de la diplomacia pública. En este caso, la marca territorio queda reducida a una herramienta de imagen con capacidad de influir directamente en el incremento de las exportaciones o en la atracción de capital económico o humano (Hernández-Alonso, 2012).

Una tercera visión indica que la marca territorio y la diplomacia pública son conceptos similares pues tienen los mismos objetivos al perseguir la creación 
de una imagen positiva del territorio y al ser una herramienta para las relaciones internacionales. En palabras de Van Ham ambas son "una revisitación de las relaciones internacionales en las sociedades postmodernas" (2008:147).

A pesar de la gran discrepancia conceptual, en todo caso, son dos conceptos que guardan una estrecha relación entre sí y que necesitan de un enfoque compartido y de un alineamiento en las prácticas territoriales, como ha puesto en valor la creación, en 2005, de la revista Place Branding and Public Diplomacy.

El diálogo, en las prácticas públicas, entre estos dos conceptos relacionados, es explicitado recientemente por Carbone (2017). Para este autor, las agendas de las marcas territorio, especialmente de las marcas destino, deben alinearse con las acciones de diplomacia pública de un territorio. Por un lado, una marca destino tiene vocación potencial para ser vehículo de acciones para la mejora del conocimiento mutuo entre sociedades ya que promueve experiencias para el conocimiento del patrimonio tangible e intangible del territorio (diplomacia pública cultural). Por otro lado, una marca destino debe radicarse en los valores culturales locales para ser identificada como única y diferencial. Ambas, diplomacia pública y marca destino necesitan de la conservación, de la puesta en valor y de la comunicación efectiva del patrimonio cultural (entendida como manifestaciones tangibles e intangibles culturales base de la identidad territorial) para la realización de sus fines.

\subsection{Factores influyentes en la legitimidad de las políticas públicas de reputación de los territorios}

Como antecedentes más relevantes que permitirán identificar aspectos clave para la legitimidad de las políticas públicas de reputación de los territorios, se puede señalar, que ya en el 2004, Hankinson, como precursor de la perspectiva relacional en place branding, indica en su clásico modelo, que la marca territorio tiene cuatro componentes que se relacionan entre sí. Éstos 'hard' o tangibles como las 'Infraestructuras' (como las infraestructuras de trasnporte) o los 'Productos y Servicios' (como los servicios turísticos y la oferta comercial de un territorio) y 'soft' o intangibles como las relaciones con 'Públicos' y las 'Comunicaciones'.

Por su especial naturaleza en lo que afecta a la reputación y legitimidad se ahonda en los citados elementos 'soft'. En cuanto a los 'Públicos', para Hankinson, una orientación hacia los públicos internos de la marca, una ausencia de conflicto o compatibilidad entre los intereses de los públicos 
internos y externos y un reconocimiento explícito de las relaciones de poder entre los públicos son fundamentales para el éxito de la marca territorio. Con respecto a las 'Comunicaciones' de la marca territorio, entiende el autor, que incluyen tanto a la comunicación espontánea que realiza los aspectos identitarios del territorio (patrimonio tangible e intangible como el paisaje, la gastronomía, las tradiciones o el carácter de sus habitantes, entre otras cuestiones) como a la comunicación estratégica de marketing (hacia los diversos stakeholders de la marca).

\section{llustración 1: Los componentes de la Marca Territorio por Hankinson (2004)}

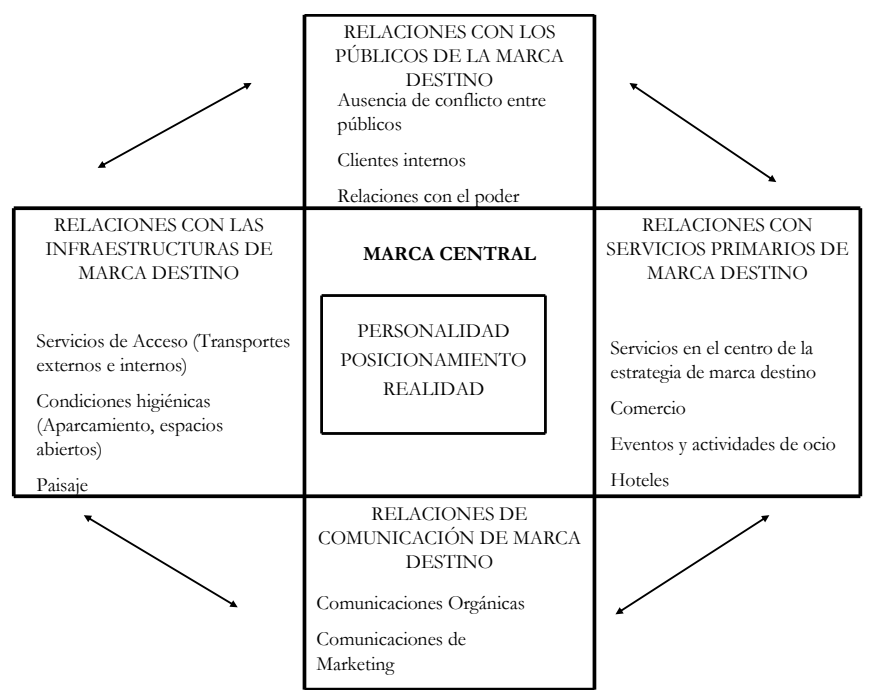

Influido por este paradigma relacional, Kavaratzis (2008) señala que las marcas territorio son un constructo de percepciones resultado de la Comunicación Primaria del territorio (compuesta por 'las Estrategias de Paisaje', 'las Infraestructuras existentes', 'determinados Comportamientos del territorio' y por su 'Estructura Organizativa') y la Secundaria (o comunicación estratégica hacia los públicos internos y externos). En concreto, Kavaratzis denomina 'Estructura Organizativa' a las relaciones existentes entre los sectores públicoprivados de la sociedad y a las redes de participación ciudadana, sostenedoras ambas de la legitimidad de la marca territorio. 


\section{Ilustración 2: Los componentes de la Marca Territorio por Kavaraztis (2008)}

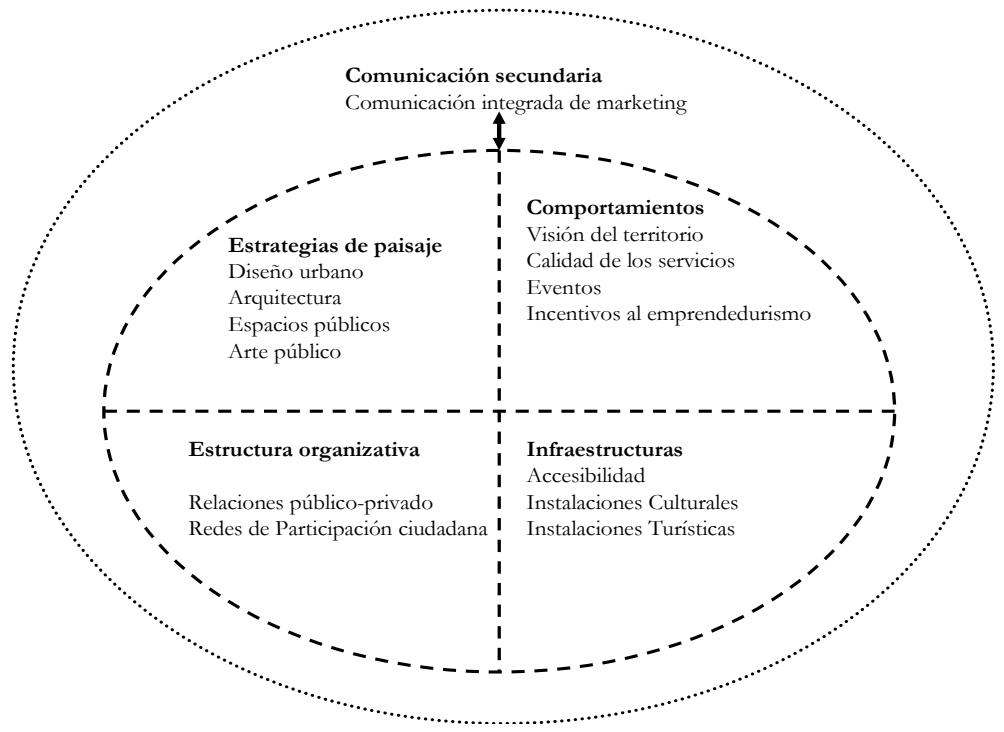

En ambos modelos (iniciales y 'clásicos' en place branding') ya aparece reconocida explícitamente la dimensión comunicacional e implícitamente, la dimensión política de las marcas territorio. Explícitamente denominada como tal, la dimensión política es reconocida recientemente en la literatura (Lucarelli, 2015).

En cuanto a su dimensión comunicacional es de destacar que una marca territorio es un relato, hegemónico y colectivo, que sirve para comunicar activa y estratégicamente los activos territoriales, interpretar el pasado, representar la realidad presente y proyectar el futuro del territorio (Pasquinelli, 2014). Genera, como resultados, un conjunto de percepciones, sentimientos y creencias sobre la reputación de un territorio que residen en la mente de los públicos (Johanson, 2012).

El reconocimiento de la dimensión política de las marcas territorio pone el foco en la necesidad de legitimidad, y sostenimiento más o menos activo de los públicos internos del territorio. Como indican Klijn, Eshuis y Braun, (2012), para que una marca territorio sea exitosa, las estrategias de marketing y de comunicación de marketing (publicidad, eventos, entre otros) deben ser desarrolladas junto con estrategias de gobernanza territorial que, mediante la participación de los públicos internos, aporten legitimidad a la marca. 
Las cuestiones clave, que se reiteran en los dos modelos 'clásicos' de Hankinson (2004) y Kavaratzis (2008), y que inciden en la legitimidad de las políticas reputacionales de marca territorio y diplomacia pública, son:

(1) La gestión de la participación de los públicos internos (de la sociedad del territorio, ciudadanos, residentes) en el diseño y desarrollo de estas políticas, (2) la creación de redes que beneficien a un conjunto sustancial y representativo de marcas públicas y privadas provenientes del territorio y

(3) la implementación de unas políticas públicas de comunicación desarrolladas estratégicamente que generen identificación con la marca y sentimiento de pertenencia en los públicos internos.

Por ello, en este artículo se reflexiona sobre los aspectos cruciales que, desde el sector público se han de tener en cuenta, en los procesos de creación y de gestión de una marca territorio y en la puesta en marcha de políticas de diplomacia pública, para que se consideren legítimas y obtengan el apoyo interno de los ciudadanos del territorio.

Como se ha señalado anteriormente se pondrá el foco en la participación de los públicos internos en el diseño y la gestión de políticas reputacionales, en los procesos de cobranding de marcas públicas y privadas del territorio y en las acciones de comunicación que se orientan o tienen en cuenta en su diseño a los públicos internos del territorio (residentes, ciudadanos).

\section{La participación de los públicos internos en las políticas reputacionales}

La literatura que analiza el papel de los públicos internos de la marca territorio es limitada y fragmentada, si bien, constata que es frecuente que exista una desconexión entre las imágenes en la mente de los públicos internos y externos de los territorios.

En la literatura se han señalado diferentes roles para los públicos internos en relación a las políticas reputacionales. Freire (2009) realiza una de las primeras aportaciones que pone luz en la importancia de los ciudadanos o residentes de un territorio como públicos internos clave en el diseño y la gestión de las políticas de reputación.

Los ciudadanos del territorio han sido identificados, desde una perspectiva más pasiva hacia otra más activa, como parte integrante de la realidad del territorio, como embajadores del territorio, como legitimadores de estas 
políticas publicas e incluso, como cocreadores de estas políticas (Eshuis, Braun y Klijn, 2013).

Desde esta última perspectiva, una marca territorio es un proceso dinámico en constante dialéctica, una co-creación entre las Administraciones Públicas (que lideran, crean infraestructuras y comunican, entre otras funciones) y los públicos internos que dotan a la marca en sus 'usos' de nuevas utilidades y significados simbólicos.

Lo que sí parece claro, es que la sociedad del territorio no puede jugar el papel de mera consumidora de las políticas públicas reputacionales. Si estas desean perdurar deben contar con el apoyo de las opiniones públicas del territorio, especialmente de las audiencias internas, pues éstas juegan un papel clave para la efectividad y el mantenimiento de estas políticas públicas a largo plazo (Kavaratzis, 2012).

Para contar con la legitimidad y el apoyo de las opiniones públicas del territorio, sus ciudadanos deben sentir que las políticas reputacionales se han diseñado contando con la participación de los públicos internos interesados más relevantes del territorio y representan la realidad de la marca, es decir, ponen el foco en la identidad territorial (Hankinson, 2004).

Los gestores de la marca debieran preguntarse ¿son los ciudadanos-residentes respetados como un socio en igualdad de condiciones que el resto en el proceso de creación y gestión de las políticas reputacionales?, ¿están representados, en el proceso de creación y de gestión de estas políticas, los públicos internos interesados más relevantes? ¿es la imagen que se desea proyectar respetuosa y ajustada a la identidad del territorio?

Según indican Zenker y Seigis (2012), la participación y el diálogo con los públicos es extremadamente relevante para el éxito de las marca territorio y son los ciudadanos-residentes el público más importante en su proceso de creación y en ocasiones, indican, el más olvidado. Habitualmente se esgrime que el establecimiento de mecanismos de participación reduce el riesgo de generación de potenciales conflictos y facilita el engagement con la marca. Para estos autores, las políticas reputacionales no sólo necesitan de la participación de los públicos internos. Indican que no es tanto la participación en si misma como el tipo de participación que se genere. Si es una "participación respetuosa" reducirá potenciales conflictos entre los gestores de la marca y los ciudadanos. Los autores consideran una "participación respetuosa" aquella que es vinculante o con capacidad de incidir en las políticas públicas. 
A esto es importante añadir, que Kavaratzis (2012) apunta a que los procesos de participación se deben llevar a cabo mediante técnicas y metodologías especialmente adaptadas a la realidad cultural del territorio.

Para Henninger, Foster y Alevizou (2016) resulta muy relevante cómo se produce el proceso de elección de los públicos que participan en las políticas. Para estos autores, las Administraciones Públicas han de seleccionar a unos stakeholders primarios que a su vez seleccionan a otros, creando redes de públicos. Es decir, existirían varios niveles de stakeholders, primarios, secundarios, terciarios... que no pueden ser elegidos de manera unidireccional por la Administración Pública para ser reconocidos como legítimos representantes de la sociedad civil del territorio.

De esto se deduce que, el proceso de creación y gestión de las políticas públicas reputacionales es un proceso de gobernanza, tiene carácter interactivo, relacional y una compleja interdependencia de los actores implicados.

Este proceso de gobernanza puede generar procesos de stakeholder engagement o de contestación 'veto power'. Por ello, las prácticas reputacionales fuertemente centralizadas en las Administraciones Públicas y poco relacionales con la sociedad del territorio, encontrarán límites en su desarrollo; es decir, movimientos contrarios a la marca, situaciones de conflicto y/o resistencia pasiva o activa (Klijn, Eshuis y Braun, 2012).

Y no sólo se trata de evitar potenciales conflictos, sin comportamientos 'a favor de la marca' mantenidos en el tiempo por parte de la sociedad del territorio, las políticas reputacionales no podrán ser efectivas a corto ni mantenerse en el medio y largo plazo (Go y Trunfio, 2012).

En este sentido, cuando los ciudadanos participan como actores políticos y se convierten en actores de la sociedad civil, aunque con diferentes grados de compromiso activo; legitiman, son embajadores y co-creadores de las políticas reputacionales (Kavaratzis y Kalandides, 2015).

Por tanto, ni las marcas territorio ni las políticas de diplomacia pública se pueden 'aplicar de afuera adentro ni de arriba abajo' (Go y Trunfio, 2012), sino que deben ser el resultado de una "narrativa colectiva de marca" (Kavaratzis y Hatch, 2013) que favorezca la cohesión social en el territorio y el diálogo entre las imágenes internas y externas. En definitiva, como ya apuntaban Hankinson (2004) y Kavaratzis (2008), las Administraciones 
Públicas deben mantener un comportamiento relacional si desean motivar y activar determinados comportamientos en los stakeholders internos favorables a sus políticas reputacionales (Go y Trunfio, 2012).

\subsection{Tipologías empíricas de relaciones de colaboración y conflicto entre actores de la sociedad civil y las políticas públicas reputacionales de marca territorio}

Se exponen a continuación ejemplos reales de cómo los movimientos ciudadanos organizados pueden boicotear o favorecer el desarrollo de una marca territorio con el fin de recalcar el importante rol legitimador de la sociedad de un territorio con respecto a las políticas públicas reputacionales.

\section{Los movimientos ciudadanos de boicot a la marca territorio.}

Zenker y Petersen (2014) han identificado diferentes plataformas civiles creadas en ciudades europeas como Hamburgo ('Not in our name'), Ámsterdam ('I'm Amsterdamned') y Birmingham (Birmingham it's not shit') contrarias a las marcas territorio que se han creado desde las respectivas Administraciones Públicas sin participación ciudadana.

Un caso paradigmático que destacan los autores es el de Birmingham, en el que el bloguero Jon Bounds realizó un manifiesto ${ }^{2}$ que fue apoyado por miles de personas y que sirvió para crear una opinión pública negativa en la ciudad y reconducir un proyecto de marca ciudad que conllevaba atracción masiva al centro de la ciudad de 'clases creativas' internacionales y el consiguiente riesgo de generación de procesos de gentrificación en el centro urbano.

\section{Los movimientos ciudadanos a favor de la marca territorio.}

Zenker y Erfgen (2014) ponen en valor que los movimientos ciudadanos pueden también liderar y sostener eventos y actividades muy relevantes para las políticas reputacionales del territorio. En este sentido, Fassio (2009) destaca el caso de los pro loco italianos. Los pro loco o asociaciones 'a favor del territorio' son grupos espontáneos compuestos por voluntarios para la promoción de la identidad territorial que funcionan en las localidades, especialmente en los pequeños municipios, como un mecanismo social de agregación y de gestión activa del tiempo de ocio. Realizan actividades de información turística y organizan eventos de naturaleza festiva, gastronómica (sagras), artesana, entre otros, que son 'metáforas del estilo de vida italiano' 
con diferentes grados de repercusión económica en el territorio. Las actividades programadas por las pro loco son autofinanciadas mediante los recursos generados por los eventos, las aportaciones voluntarias de los residentes y cuentan con una participación presupuesta variable de las Administraciones Públicas.

Los movimientos voluntarios pro loco existen en más de 6.000 municipios italianos asociados en la Unione Nazionale delle Pro Loco d'Italia coordinadora de proyectos comunes entre diferentes pro loco locales. Estos eventos de identidad territorial, organizados y gestionados por asociaciones civiles de voluntarios en red, cuyos interlocutores principales son las Administraciones Públicas del Estado en sus diferentes niveles, se configuran en ocasiones como auténticos eventos de marca territorio con una componente importante en la configuración de los activos de las marcas destino públicas.

3. Las redes de marcas públicas y privadas. Cobranding y arquitectura de marcas como estrategia de legitimidad en las políticas reputacionales

Dos son las cuestiones que de manera más importante condicionan la necesidad de operar en red, por parte de las Administraciones Públicas, al llevar a cabo políticas reputacionales, creando un universo de relaciones entre las marcas públicas y privadas del territorio. En primer lugar, las Administraciones Públicas, son interdependientes de otros actores del territorio que mantienen visiones diferentes, e incluso conflictivas entre si, para el desarrollo de sus políticas. Por este motivo, las políticas reputacionales necesitan de la cooperación y coproducción público-privada y de relaciones multisectoriales y multinivel en la formulación y aplicación de estas políticas públicas. Es decir, es necesaria, tanto la coordinación interadministrativa en el diseño y gestión de las políticas reputacionales que afectan al territorio como la cooperación de las principales marcas privadas del territorio que operan internacionalmente.

Los problemas de coordinación interadministrativa son muy relevantes y generan gran pérdida de posicionamiento para el territorio, sobre todo, cuando Administraciones Públicas de niveles diferentes y con distintos objetivos funcionales operan en los mismos mercados internacionales emitiendo mensajes distintos o incongruentes (Klijn, Eshuis y Braun, 2012). Esta carencia de coordinación interadministrativa (entre Estado central, regiones, provincias, ciudades...) puede ser el resultado de problemas políticos y emitir un mensaje de debilidad institucional en el territorio.

En segundo lugar, dada su naturaleza multistakeholder y el pluralismo y complejidad de la sociedad a la que representan, las políticas reputacionales se 
encuentran con dificultades a la hora de generar un 'único argumento de venta' para el territorio.

Para el marketing corporativo crear una marca comercial es crear una propuesta única y distintiva de valor que trasladar con un posicionamiento claro a la mente de los públicos (Trout y Ries, 2000). Pero ¿es posible aplicar esto en los territorios? No existe una respuesta única en la literatura.

Los territorios son realidades complejas que poseen beneficios muy diferentes para sus públicos internos y externos, entre otras funcionalidades, pueden ser lugares para vivir para unos, lugares donde invertir para otros o lugares para veranear para otros tantos. Integrar toda esa diversidad es mucho más complejo que en las marcas comerciales y por eso, para Johanson (2012) los territorios necesitan cierta inconsistencia o 'plasticidad' en la creación de su identidad de marca.

Las distintas percepciones que un territorio provoca son el es resultado de una larga historia y de asociaciones heterogéneas y complejas, y esto lleva a autores como Zenker y Beckmann (2013), a solicitar la necesidad de generar en los territorios políticas activas de cobranding entre marcas públicas y privadas.

Las dos cuestiones anteriormente señaladas provocan que si en el territorio las diferentes marcas públicas y privadas más relevantes no cooperan entre sí, además generar problemas en la legitimidad social (interna) de este tipo de políticas públicas, se puede poner en peligro la congruencia de las imágenes que emite el territorio al quedar éstas superpuestas o no alineadas.

Entonces el reto está en cómo respetar, cuidar y poner en valor la diversidad identitaria en los territorios, como propósito ajustado a la naturaleza y fines de las Administraciones Públicas, y a su vez, desarrollar políticas públicas reputacionales congruentes. Porque, en primer lugar, si la identidad territorial proyectada es demasiado simple y única, aunque facilite a priori la 'comercialización' del territorio, puede contribuir a la pérdida de diversidad de las identidades territoriales, a la 'comoditización' del territorio y a problemas de identificación de los públicos internos con las políticas reputacionales (Zavattaro, 2010). Y en segundo lugar, se puede dar el caso de que las imágenes proyectadas no tengan coordinación entre sí porque las políticas reputacionales operen de manera independiente sin una relación jerárquica o coordinada en la construcción de la identidad entre territorios de menor y mayor escala jurídica. Los territorios de una misma realidad jurídica (ciudades, regiones) pueden construir su identidad marca en función de los mercados hacia los que se desean proyectar con independencia de las estrategias que se desarrollen a nivel nacional o estatal. A la larga esto, puede plantear problemas de fragmentación en la percepción externa de algunos territorios 
(especialmente de los países/Estados) y tener un efecto negativo made in o 'lugar de origen' de naturaleza económica, además de evidenciar problemas políticos en la estructura de gobierno central del territorio.

Estos desafíos tienen básicamente tres posibilidades de respuesta en cuanto a las estrategias de cobranding que son el resultado de una determinada visión para el territorio. Al modo en el que se establecen las relaciones formales entre las marcas se le denomina en marketing 'arquitectura de marcas'.

Las tres estrategias principales para realizar cobranding son las denominadas 'monolítica', 'de respaldo' y 'multimarcas'. La decisión adoptada no es baladí, pues de ésta resultarán condicionadas las relaciones culturales, económicas y políticas entre las diferentes marcas del territorio tanto públicas como privadas.

Por tanto, un territorio puede ser entendido como el conglomerado de muchas marcas que representan públicos distintos con intereses diversos. El diseño y el mantenimiento de una estrategia, o el viraje hacia otra, denota que unos intereses han predominado sobre otros en el diseño de la estrategia para el territorio.

En sus respuestas, los territorios tienen que decidir ante la tensión de apostar por una presentación más compleja y ajustada a la realidad del territorio que favorecerá la posibilidad de identificación de sus ciudadanos o una presentación más simple que beneficiará el reconocimiento de los públicos externos.

Autores como Ooi (2011) indican que una marca territorio debe simplificar los mensajes hacia sus públicos externos y basarlos en imágenes simples o estereotipos 0 que faciliten "un marco mental en el que imaginar y experimentar el territorio (...) en forma de dibujo o envoltorio del lugar" (p.57). En cambio, en su propio territorio, una marca territorio es una realidad compleja que debe reflejar la diversidad de la sociedad local. Este aspecto nos conduce a reflexionar en el punto cuatro sobre cómo plantear una comunicación de marca que cuente con los públicos internos y que favorezca la legitimidad de las políticas reputacionales.

\subsection{Tipologías empíricas de cobranding y arquitectura de marcas}

Como hemos señalado en el apartado anterior los comportamientos ante el cobranding entre marcas públicas y privadas puede ser muy distintos y reflejar diversas estrategias comunicacionales y concepciones políticas de un territorio. 
Veamos dos tipologías empíricas que se ajustan a las estrategias 'monolítica' y 'de respaldo'.

Colombia. Relaciones entre la marca país, las marcas ciudad y las marcas sectoriales para actividades económicas clave

La marca país Colombia apuesta por una arquitectura monolítica, con 'arquitectura variable' en su diseño gráfico, para todas las manifestaciones y políticas que se generaran desde el Estado central tanto a nivel turístico, económico, cultural o deportivo, entre otros. De este modo, no opta por hacer coexistir una marca destino (orientada a los turistas) y una marca país, ni marcas sectoriales para sectores económicos clave, como ha realizado España, entre otros países. Se presentan a modo de ejemplo, identidades destinadas a la promoción del turismo de naturaleza y a la promoción de las exportaciones internacionales.

\section{Ilustración 3.}

\begin{tabular}{|c|c|}
\hline $\begin{array}{c}\text { IVC de la } \\
\text { Marca País }\end{array}$ & $\begin{array}{r}\text { Aplicaciones de la IVC de la Marca País al sector } \\
\text { turístico y exportador }\end{array}$ \\
\hline colom:14 & colom:314
\end{tabular}

En el desarrollo de las marcas de región y de ciudad, mediante una arquitectura de respaldo, sigue los principios de los que parte la marca país.

De este modo, Colombia apuesta por una imagen de país fuerte en el que sus regiones y ciudades (como marcas públicas) y sus sectores económicos (que amparan a marcas comerciales privadas estratégicas) se apalanquen bajo la marca estatal. 


\section{Ilustración 4}

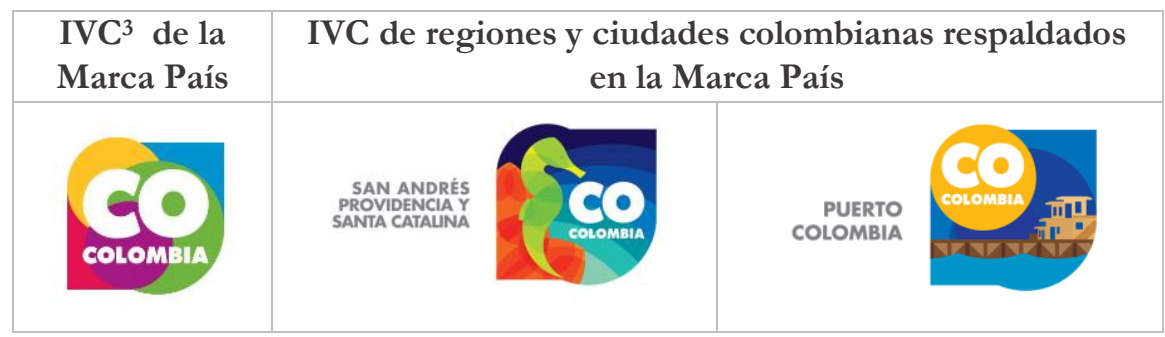

Dicho con las propias palabras de la marca "cuando existe una marca país fuerte, lo más correcto es que la marca ciudad se apalanque en la marca país, haciendo énfasis en sus atributos diferenciales pero enmarcados estos dentro de la estrategia general del país, para de esa manera hacer que ambos esfuerzos apunten a una misma dirección y sus resultados beneficien a todas las partes involucradas"4.

\section{Alicante. La marca destino Costa Blanca (Alicante - España) y sus submarcas.}

La marca Costa Blanca nace hace cincuenta años, junto con el resto de marcas 'Costa' que salpican el litoral español (Costa del Sol, Costa Blanca, Cosa Brava, Costa Cálida, Costa del Azahar, entre otras), con el fin de representar al turismo de sol y playa de la provincia de Alicante .

Desde el año 2015 está evidenciando un profundo cambio de estrategia al abandonar la estrategia monolítica y evolucionar a una de respaldo. En sus propias palabras la marca evoluciona hacia una 'familia' de marcas ${ }^{5}$. Ya en este año, demuestra una nueva vocación de respaldar mediante la creación de las dos submarcas con referencia al territorio 'Playas' e 'Interior' y de siete submarcas sectoriales, no sólo a los municipios de costa y el turismo de sol y playa, sino a toda la diversidad socioeconómica y geográfica de una provincia con diversos clusters industriales y un amplio territorio de interior (montañoso y agrícola).

En 2017, al ser la primera (y a fecha de hoy única) marca 'Costa' en incluir la referencia a España en su identidad visual, evidencia una mayor vocación internacional para la captación de nuevos segmentos de clientes referenciándose a las fortalezas de España como una potencia mundial a nivel 
turístico. A continuación se expone la evolución gráfica sufrida entre 2015 y 2017 (Patronato de Turismo Costa Blanca, 2017).

\section{Ilustración 5}

2015

\section{(1) CostaBlanca}

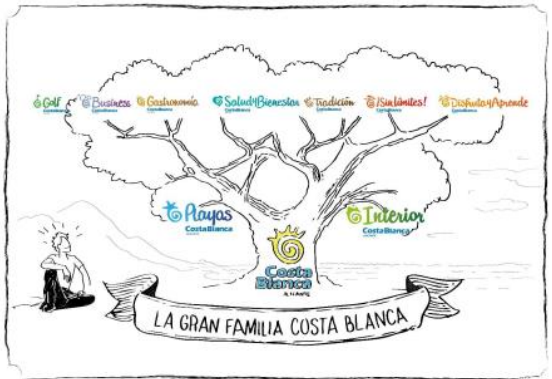

2017

CostaBlanca"

ALICANTE. SPAIN

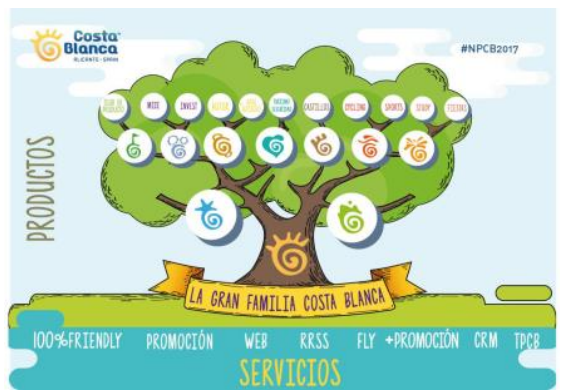

\section{La comunicación para la legitimidad en las políticas reputacionales}

Como se señalaba anteriormente, una comunicación de las políticas reputacionales excesivamente simplificada y enfocada sólo en los públicos externos podría generar problemas en los territorios (Govers, 2013). Se puede dar el caso de que si se emiten mensajes excesivamente simples y estereotipados a la sociedad del territorio, ésta pueda sentir que se banaliza la 'identidad territorio' con fines comerciales y se sienta poco comprometida con las políticas públicas reputacionales (Kavaratzis, 2012).

Además del mensaje, para Pasquinelli (2013) el 'lenguaje' y el 'estilo de comunicación' adoptado por las Administraciones también influye en la formación de los significados. Por tanto, los mensajes, los lenguajes y los estilos de comunicación deben resultar de la cooperación entre los stakeholders clave del territorio y deben favorecer la mediación entre realidades diferentes, posibilitar nuevas interacciones entre actores y fortalecer las relaciones ya existentes (Ooi, 2011). 
Desde esta visión, la función de las Administraciones Públicas es la de desencadenar la discusión, la participación y la movilización de intereses diversos en colaboración o conflicto, en torno a la idea sobre la que se quiere crear una narrativa para el territorio.

En este sentido, y resultado del diálogo y la negociación, tanto en los proyectos de marca territorio como en las políticas de diplomacia pública, resulta necesario el establecimiento de narrativas compartidas entre los públicos interesados internos. Además de los Estados, las regiones, las ciudades $^{6}$, las empresas privadas del territorio y los actores de la sociedad civil, son agentes activos en las políticas de marca territorio y de diplomacia.

Incorporar a las empresas privadas y a colectivos y miembros destacados de la sociedad civil (personalidades reputadas, líderes de opinión, entre otros) a las acciones de diplomacia pública contribuye a generar una imagen positiva del territorio y hace que ganen en credibilidad los proyectos de marca territorio (de Beer y van Buitenen, 2016). Hágase notar que uno de los principales riesgos a los que se enfrenta la comunicación de las políticas reputacionales es que ésta sea sentida por los residentes como propaganda política del Estado o 'artefacto' de marketing sin vinculación con la sociedad del territorio (Kavaratzis, 2012).

Básicamente, en las prácticas, se han identificado dos modos de implicar a los públicos internos en la comunicación de este tipo de políticas: siendo consumidores y diseñando acciones de comunicación específica hacia los públicos internos con el fin de potenciar su sentido de identificación con las políticas reputacionales y sus comportamientos activos como embajadores del territorio y siendo productores de comunicación y haciendo participes a los públicos internos como distribuidores virales y cocreadores de acciones de comunicación dirigidas a públicos externos (publicidad, eventos, entre otros). En este sentido, destaca la creación de comunidades virtuales en las que compartir experiencias de marca.

\subsection{Tipologías empíricas de acciones de comunicación interna en políticas públicas reputacionales}

\section{La marca destino Elche Oasis del Mediterráneo (Elche-Alicante- Comunidad Valenciana-España).}

En 2012 se crea la marca destino Elche Oasis del Mediterráneo con el objetivo de reposicionar una ciudad que tradicionalmente había sido reconocida por la 
industria del calzado y apalancar las fortalezas turísticas en sus activos únicos, especialmente aquellos distinguidos como Patrimonios Culturales UNESCO de la Humanidad como el Palmeral ilicitano ${ }^{7}$.

En el proceso de consolidación de esta marca se diseña una campaña de comunicación interna dirigida a la potenciación del orgullo ciudadano y a la identificación con la marca de los ciudadanos ilicitanos y de los colectivos que se estiman clave para la experiencia de marca turística (camareros, taxistas, policías locales, dependientes de comercio, recepcionistas en hoteles, trabajadores del servicio de limpieza o jardinería municipal, entre otros).

Los objetivos últimos de esta campaña son el cambiar la percepción interna de la propia ciudad, de industrial hacia un destino turístico y la legitimación de esta estrategia de desarrollo territorial. Se presentan algunas de las imágenes que se desarrollaron en diversos soportes publicitarios (mupis, vallas, publicidad en red de autobuses municipales, entre otros) y en medios de comunicación distintos (radio, prensa escrita, televisión local, publicidad exterior, página web).

\section{Ilustración 6}
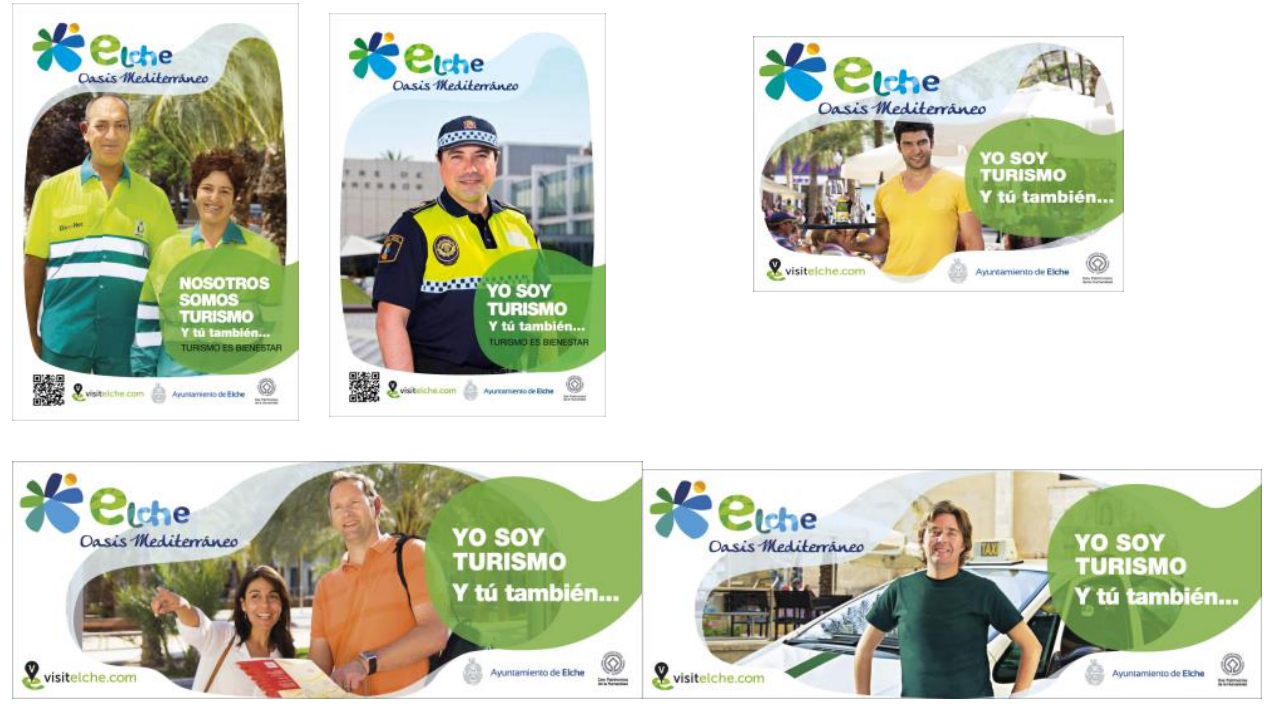

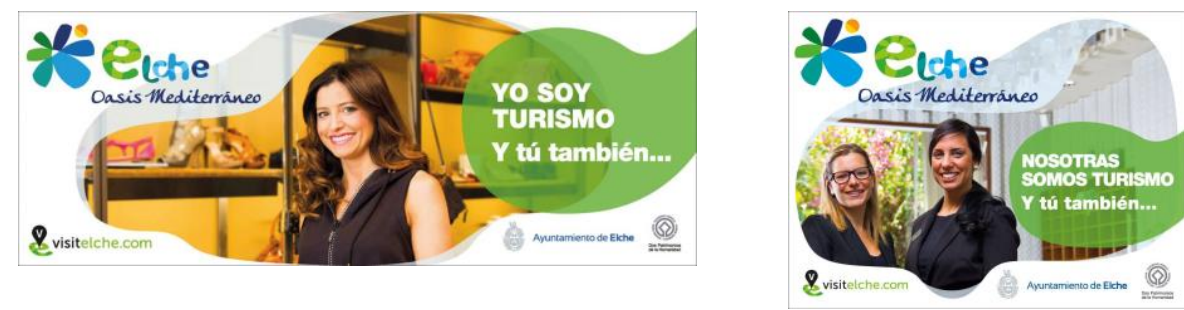

\section{La marca destino Comunitat Valenciana (España)}

Las abajo mencionadas son las palabras textuales con la que la marca destino Comunitat Valenciana presenta su campaña en su web oficial. El destino crea un espacio virtual en el que los propios residentes de la Comunitat o turistas que ya la han visitado comparten sus experiencias, sus afectos hacia lugares o eventos y realizan recomendaciones específicas para futuros visitantes.

"Descubre aquí los mejores planes capturados por locales y visitantes en redes sociales. Utiliza la etiqueta \#mediterráneoenvivo para ver todo lo que ocurre en nuestra Comunidad"s.

Esta campaña se apalanca en valores identitarios y culturales locales con el fin de que los residentes del territorio sean creadores activos de información y comunicación turística de servicio público. Sean, en definitiva, además de usuarios de la propia comunicación, prescriptores, embajadores y cocreadores de las experiencias sugeridas por el destino.

El objetivo último trata de generar 'comunidades on line' que refuercen el proyecto de creación de la marca destino o 'comunidad territorial', con valores identitarios propios, muy vinculados a la 'experiencia real' del destino.

Este espacio virtual favorece la hipersegmentación en las estrategias comunicacionales y relacionales hacia los diferentes públicos y la participación de éstos en la distribución y cocreación de los mensajes de marca. De este modo, la marca territorio Comunitat Valenciana se enfrenta al reto de crear una 'comunidad de pertenencia virtual', una suerte de espacio 'en la red' para el desarrollo de la identidad simbólica mediterránea y la expresión de las emociones sobre el territorio por parte de los locales y que, en paralelo, beneficia la participación comunitaria en la construcción del relato sobre el 
territorio, la legitimidad de la marca, su notoriedad y por tanto, el posicionamiento y la competitividad socioeconómica de la marca destino.

\section{Consideraciones Finales}

Las políticas reputacionales juegan un papel cada más importante en las políticas públicas de Estados, regiones y ciudades en un mundo globalizado en el que la gestión de la influencia y del soft power son considerados estratégicos. Estas políticas reputacionales aunque lideradas o dinamizadas desde lo público no se pueden llevar a cabo con éxito al margen de los sectores privados de la sociedad. Empresas internacionalizadas o con vocación de serlo, asociaciones civiles, movimientos ciudadanos, líderes de opinión, Universidades e investigadores científicos, son actores activos y estratégicos en la gestión de la reputación de los territorios.

Las políticas reputacionales públicas han de manifestar con hechos una orientación relacional para ser legitimadas por los públicos internos del territorio y contar con comportamientos de sostenimiento activo. Para ello, han de considerar la gestión de las relaciones y de las comunicaciones con los públicos internos, como áreas clave en el desarrollo de sus políticas reputacionales 'hacia fuera', pues éstas permitirán o inhibirán la generación de marcas territorio poderosas y de una reputación positiva para el territorio mantenida en el tiempo.

Esto tiene implicaciones en el modo con el que los gestores de la marca territorio diseñan y desarrollan este tipo de políticas públicas. El enfoque en la práctica ha de evolucionar de un estilo que en muchas ocasiones no supera lo 'publicitario-propagandístico' a un enfoque relacional, tanto en sus prácticas participativas como comunicacionales, entendiendo que una marca territorio al ser un instrumento para la gobernanza del territorio ha de gestionar redes de stakeholders (internos y externos, públicos y privados) y fomentar su implicación activa en el diseño y gestión de estas políticas públicas.

Establecer mecanismos y canales reales participación de los ciudadanos, empresas y colectivos del territorio, evitar la ineficaz sobre-fragmentación y desconexión de las marcas públicas que hacen referencia al territorio con mayor coordinación inter-administrativa y cooperación público-privada y atender activamente a la comunicación interna mediante el uso de técnicas comunicacionales que favorezcan el engagement de la sociedad del territorio con la marca, son tres líneas de trabajo a los que los gestores de las marcas 
territorio y de las políticas reputacionales de los destinos deberán atender con el fin de mejorar la legitimidad de este tipo de políticas públicas.

\section{Bibliografía}

Anholt, S. (2007). L’identità competitiva. Il branding di nazioni, città, regioni. Milano: Egea.

- (2008). "Place branding: Is it marketing, or isn't it?”. Place Branding and Public Diplomacy, 4(1), 1-6.

Carbone, F. (2017). "International tourism and cultural diplomacy: a new conceptual approach towards global mutual understanding and peace through tourism". Tourism Review, 65(1), 61-74.

De Beer, I. y van Buitenen, A. (2016). "Leveraging stakeholder interest in public diplomacy: The case of the Hague Peace and Justice Project". Place Branding and Public Diplomacy, doi:10.1057/s41254-016-0003-0.

De San Eugenio-Vela, J. (2013). "Del Estado-nación al Estado-marca. El rol de la Diplomacia Pública y la Marca País en el nuevo escenario de las relaciones internacionales". Revista de Estudios Sociales, 46, 145-157.

_ - (2012). Teoria i mètodes per a marques de territori. Barcelona: Editorial UOC.

Eshuis, J., Braun, E. y Klijn, E. H. (2013). "Place marketing as governance strategy: An assessment of obstacles in place marketing and their effects on Attracting target groups". Public Administration Review, 73(3), 507-516.

Fassio, G. (2009). L'elogio del villano: le sagre in piazza. Roma: Editorial ARACNE.

Freire, J.R. (2009). "Local people a critical dimension for place brands". Brand Management, 16(7), 420-438.

Go, F. y Trunfio, M. (2012). "A paradigm shift from tourism destination management to democratic governance of place branding: the cases of Pompei and Campi Flegrei”. Journal of Travel and Tourism Research, Special Issue Destination Management. 
Govers, R. (2013). "Why place branding is not about logos and slogans". Place Branding and Public Diplomacy, 9(2), 71-75.

Hankinson G. (2004). "Relational network brands: towards a conceptual model of place brands”. Journal of Vacation Marketing, 10, 109-121.

Henninger, C.H., Foster, C. y Alevizou, P.J. (2016). "Stakeholder engagement in the city branding process". Place Branding and Public Diplomacy, ISSN 1751-8040 (In Press).

Hernández-Alonso, F.J. (2012). Diplomacia pública y place branding: El estado de la marca España. La Coruña: Netbiblo.

Johansson, M. (2012). "Place Branding and the Imaginary: The Politics of Reimagining a Garden City”. Urban Studies, 49 (16), 3611-3626.

Kavaratzis, M. (2008). From city marketing to city branding: An interdisciplinary analysis with reference to Amsterdam, Budapest and Athens. (Tesis doctoral). Recuperado de goo.gl/GPBgw7.

_ - (2012). 'From 'necessary evil' to necessity: stakeholders' involvement in place branding”. Journal of Place Management and Development, 5 (1), 7-19.

_ -y Hatch, M. J. (2013). "The dynamics of place brands: An identity-based approach to place branding theory". Marketing Theory, 13(1), 69-86.

_ -y Kalandides, A. (2015). "Rethinking the place brand: the interactive formation of place brands and the role of participatory place branding". Environment and Planning A, 47, 1368-1382.

Klijn, E., Eshuis, J. y Braun, E. (2012). “The Influence of Stakeholder Involvement on The Effectiveness of Place Branding”. Public Management Review, 14 (4), 499-519.

Lucarelli, A. (2015). The Political Dimension of Place Branding. Stockholm Business School, Stockholm University (tesis doctoral).

Manfredi, J. L. (2011). "Hacia una teoría comunicativa de la Diplomacia Pública”. Comunicación y Sociedad, 25(2), 199-225. 
Merkelsen, H. y Rasmussen, R.K. (2016). "Nation branding as an emerging field-An institutionalist perspective". Place Branding and Public Diplomacy, doi: 10.1057/s41254-016-0018-6.

Noya, J. (2005). El poder simbólico de las naciones, Real Instituto El Cano. España. Documento de Trabajo (DT) 35 /2005.

Ooi, C. (2011). Paradoxes of City Branding and Societal Changes. En Dinnie. K. (Eds.), City Branding Theory and Cases (pp. 54-61). London: Palgrave Macmillan.

Pasquinelli, C. (2013). "Branding as Urban Collective Strategy-making: the formation of NewcastleGasteshead's Organisational Identity". Urban Studies, $00,1-17$.

_ - (2014). "Branding as Urban Collective Strategy-making: The Formation of Newcastle Gateshead's Organisational Identity". Place Branding and Public Diplomacy, 51(4), 727-743.

Patronato de Turismo Costa Blanca (2017). Plan de Acción Costa Blanca 2017 (documento interno inédito). Alicante.

Trout J. y Ries A. (2000). Posicionamiento. La Batalla por su mente. London: Mc Graw Hill.

van Ham, P. (2008). "Place Branding: The State of the Art". The Annals of The American Academy of Political and Social Science, 616 (1), 126-149.

Visitelche (2012a). Campaña de Sensibilización Marca Destino (documento interno inédito). Elche (Alicante).

_ - (2012b). Plan de Marketing Elche Oasis del Mediterráneo. Recuperado de goo.gl/N2aBHP.

Zavattaro, S.M. (2010). "Municipalities as Public Relations and Marketing Firms". Administrative Theory \& Praxis, 32 (2), 191-211.

Zenker, S. y Beckmann, S. C. (2013). "My Place is not Your Place-Different Place Brand Knowledge by Different Target Groups". Journal of Place Management and Development, 6 (1), 6-17.

— -y Erfgen, C. (2014). "Let them do the work: a participatory place branding approach". Journal of Place Management and Development, 7(3), 225-234. 
— -y Petersen, S. (2014). "An integrative theoretical model for improving resident-city identification”. Environment \& Planning A, 46(3), 715-729.

_ -y Seigis, A. (2012). "Respect and the city: the mediating role of respect in citizen participation". Journal of Place Management and Development, 5 (1), 20-34.

Zeraoui, Z. y Castillo-Villar, F.R. (2016). "La paradiplomacia de la ciudad. Una estrategia de desarrollo urbano". Revista del CLAD Reforma y Democracia, 65, 225-242.

\section{Notas}

1 Los modelos de Hankinson (2004) y Kavaratzis (2008) se reproducen literalmente por la autora de este artículo, limitándose ésta a realizar una traducción de los mismos. Los citados modelos pueden ser consultados en su idioma original en las obras referenciadas.

2 Para más información sobre este movimiento contestatario al proyecto de marca territorio la autora recomienda la lectura del manifiesto completo, publicado en http://www.buback.de/nion/.

${ }^{3}$ El acrónimo IVC corresponde a Identidad Visual Corporativa.

${ }^{4}$ Texto e imágenes extraídas de la web oficial de la marca país http:/ / www.colombia.co/esta-es-colombia/preguntas-sobre-

colombia/porque-una-marca-ciudad/ (consultado el 24 de abril de 2017).

5 http://www.costablanca.org/Esp/ (consultado el 24 de abril de 2017).

6 La diplomacia pública ejercida por ciudades y regiones, es decir, por estructuras intermedias del Estado, se ha denominado también Paradiplomacia (Zeraoui y Castillo-Villar, 2016).

7 http://www.visitelche.com/ (consultado el 24 de abril de 2017) y Visitelche (2012b).

8 Texto extraído de la web oficial de la marca destino (consultado el 24 de abril de 2017). http://mediterraneoenvivo.comunitatvalenciana.com/ 


\section{Agradecimientos}

Debemos agradecer al Patronato de Turismo de la Costa Blanca de la Diputación Provincial de Alicante, al organismo autónomo para la gestión turística Visitelche del Ayuntamiento de Elche (Alicante), a la Agencia Valenciana de Turismo de la Comunitat Valenciana y a la Marca País Colombia tanto por la colaboración en este artículo como por el permiso dado para la utilización de sus políticas, ejemplos e imágenes como ejemplos de buenas prácticas. Especial es el caso de la Marca País Colombia-ProColombia pues ha tenido a bien nombrarme, el 7 de abril del 2017, embajadora de la Marca País. 


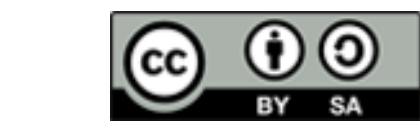

Licencia Creative Commons

Miguel Hernández Communication Journal

mhjournal.org

\section{Cómo citar este texto:}

María José Cerdá Bertomeu (2017): "Participación y Comunicación. Hacia la legitimidad de las políticas públicas de reputación de los territorios", en Miguel Hernández Communication Journal, nº, pp. 643 a 669. Universidad Miguel Hernández, UMH (ElcheAlicante). Recuperado el - de de 20_ de: link del artículo en mhjournal.org] 